carbohydrate level, but the aerobic acid formation $\left(Q_{G}^{\mathrm{O}_{2}}\right)$ rises to a value near or equal to that normally found only under anaerobic conditions. The acid formed, estimated by Clausen's method, proves to be lactic acid.

\begin{tabular}{|c|c|c|c|c|c|c|c|}
\hline \multirow[b]{2}{*}{$\begin{array}{l}\text { Expt. } \\
\text { (min.) }\end{array}$} & \multirow[b]{2}{*}{ Medium } & \multicolumn{3}{|c|}{ Control } & \multicolumn{3}{|c|}{ Phenosafranine $10^{-5} \mathrm{M}$. } \\
\hline & & $Q_{\mathrm{O}_{2}}$ & $Q_{G}^{O_{2}}$ & R.Q. & $Q o_{2}$ & $Q_{G}^{02}$ & $R . Q$. \\
\hline 100 & Bicarb. & $-11 \cdot 5$ & $+2 \cdot 0$ & -1 & $-14 \cdot 9$ & $+15 \cdot 2$ & - \\
\hline $\begin{array}{r}90 \\
120\end{array}$ & $\begin{array}{l}\text { Phosphate } \\
\text { Bicarb. }\end{array}$ & $\begin{array}{l}-12 \cdot 8 \\
-13 \cdot 2\end{array}$ & $+\overline{1 \cdot 7}$ & $\begin{array}{l}1.01 \\
1.02\end{array}$ & $\begin{array}{l}-11.6 \\
-14.4\end{array}$ & $+\overline{11 \cdot 1}$ & $\begin{array}{l}0.98 \\
0.98\end{array}$ \\
\hline
\end{tabular}

Thus the complete separation and simultaneous occurrence of carbohydrate oxidation and fermentation is demonstrated in intact animal cells under conditions closely approximating to the physiological.

In tumours, unlike most normal tissues, the respiration is inadequate to suppress the lactic acid formation (Warburg ${ }^{6}$ ) ; the carbohydrate oxidation is defective (Dickens and Simer ${ }^{7}$ ). Phenosafranine specifically inhibits the Pasteur mechanism in tumours also :

\begin{tabular}{|c|c|c|c|c|c|c|}
\hline & \multirow{2}{*}{ Expt. } & \multirow[b]{2}{*}{ Medium } & \multicolumn{2}{|c|}{ Control } & \multicolumn{2}{|c|}{$\begin{array}{l}\text { Phenosafranine } \\
3 \times 10^{-4} M \text {. }\end{array}$} \\
\hline & & & $Q_{o_{2}}$ & $Q_{G}^{o_{2}}$ & & $Q_{G}^{0_{2}}$ \\
\hline $\begin{array}{l}\text { Jensen } \\
\text { sarcoma }\end{array}$ & 60 & Bicarb. & $-10 \cdot 8$ & $+28 \cdot 3$ & $-9 \cdot 7$ & +44.9 \\
\hline $\begin{array}{l}\text { Walker } \\
\text { carcinoma }\end{array}$ & 30 & , & $-12 \cdot 1$ & +20.9 & $-8 \cdot 8$ & +39.5 \\
\hline
\end{tabular}

Thus whilst in both normal and tumour tissue a widespread correlation between carbohydrate oxidation and carbohydrate fermentation normally exists (Dickens and Simer ${ }^{7}$ ), phenosafranine in both groups of tissue is able, when present in extremely low concentration, to break down specifically and completely the coupling reaction between these two fundamental routes of carbohydrate katabolism in the living cell.

Cancer Research Laboratory,

F. DickeNs.

North of England Council of the

British Empire Cancer Campaign,

Royal Victoria Infirmary,

Newcastle-on-Tyne.

March 8.

1 Biochem. Z., 172, 432 ; 1926.

${ }^{2}$ ibid, 219, 432; 1930 .

${ }^{3}$ Z. physiol. Chem., 210, 79 ; 1932

: Biochem. $J_{31}$ 28, 537

ibid., 29, 157 ; 1935 .

(1926.

'Biochem. J., 24, 1301 ; 1930. 25, 985 ; 1931.

\section{Application of Low Temperature Calorimetry to Radioactive Measurements}

IT is often of importance to determine in absolute measure energy changes connected with radioactive transformations, but only in a few cases has it been possible to employ calorimetric methods for this purpose, since in general the amounts of energy liberated in unit time are too small. The sensitivity of calorimetric measurement can be increased, how. ever, by many orders of magnitude by working at very low temperatures, and it may be worth while to point this out, as low temperature technique is now within the reach of non-specialised laboratories.

Consider a calorimeter consisting of lead. At a temperature of $1 \cdot 3^{\circ}$, which can easily be obtained with liquid helium, its specific heat is 3,000 times smaller than at room temperature. So the calorimetric sensitivity is increased by this factor if we take the temperature sensitivity as constant. Using a substance like tungsten, with a higher $\theta_{\text {Debye, }}$ one can increase this factor still further by one power of 10 . If one wishes to measure the heat developed with an accuracy of 1 per cent, the temperature must be allowed to change by $1 / 10^{\circ}$, assuming that the measuring sensitivity is $1 / 1,000^{\circ}$ $1 / 10,000^{\circ}$. The effects can be accumulated over a period of at least ten minutes, as at very low temperatures the thermal insulation can be made nearly perfect, owing to the lack of radiation. Thus, using a calorimeter consisting of $1 \mathrm{~cm}^{3}$ of tungsten, one could measure $10^{-8}$ cal./sec., which is about 1,000 times more sensitive than in the calorimeter of Meitner and Orthmann ${ }^{1}$. So, for example, the total heating effect of $10^{-8} \mathrm{gm}$. of radium situated within the calorimeter could be determined, or the heating caused by the $\gamma$-rays from a source of 0.1 millicurie of radon placed $3 \mathrm{~cm}$. away from the calorimeter.

Cooling the calorimeter below $1^{\circ}$ by the magnetic procedure, one can diminish still further the specific heat of the absorbing substance, and at the same time the sensitivity of the temperature measurement is considerably increased by basing it on the susceptibility of the paramagnetic salt, for, in the region where the Curie law holds, the accuracy of temperature measurement is proportional to $1 / T^{2}$. With a substance obeying the $T^{3}$ law for the specific heat, therefore, the sensitivity of this method increases with falling temperature with $T^{-5}$.

The specific heat of a paramagnetic salt, however, does not follow the $T^{3}$ law, as its specific heat must necessarily be anomalous in this temperature region ${ }^{2}$. No great increase in sensitivity could therefore be achieved below $1^{\circ}$ by working with a calorimeter consisting of the salt alone. But, of course, this does not apply to an appropriate combination of the paramagnetic salt and an absorbing substance of non-anomalous specific heat.

In some preliminary experiments carried out during the past few weeks, Dr. Kürti and I nevertheless worked with the unfavourable case of the salt alone in order to be able to use our ordinary apparatus for magnetic cooling ${ }^{2}$. We took $1 \mathrm{gm}$. of iron am monium alum and cooled it down to $0 \cdot 05^{\circ}$, which in this case was an advantage solely because of the improved thermal insulation ${ }^{2}$. In spite of the very small absorption coefficient of the substance for $\gamma$. rays, and the comparatively low thermometric sensitivity of this particular apparatus, a sharp rise of temperature set in immediately after the substance had been exposed to the $\gamma$-radiation of 100 millicuries of radon at a distance of $2 \cdot 5 \mathrm{~cm}$. (This turned out to be a very convenient way for measuring the specific heat of the salt and we will report soon on the results.) Even in this unfavourable case, we could measure $10^{-8} \mathrm{cal} / \mathrm{sec}$. , and it should be possible to measure, in a volume of about $1 \mathrm{~cm} .^{3}$, an evolution of heat of the order of $10^{-11} \mathrm{cal} / \mathrm{sec}$, by using a suitable absorbing substance in combination with the paramagnetic salt and improving the sensitivity of the temperature determination.

With such increased sensitivity, various problems can be attacked, and experiments in this direction are in progress at the Clarendon Laboratory.

Clarendon Laboratory, F. Simon.

Oxford.

March 28.

' I. Meitner and W. Orthmann, Z. Phys., 60, 143; 1930.

${ }^{2}$ N. Kürti and F. Simon, Proc. Roy. Soc., A, 149, $152 ; 1935$ 